\title{
Something Different
}

\section{Health education by children for children}

\author{
RICHARD SMITH
}

What could be more unusual than two 11-year-olds teaching 15 -year-olds in a youth club about fetal development ? Yet this is only one of many projects that have resulted from the founding of a children's health club in Lambeth. The club started in 1977 when two 9-year-old boys knocked on the door of the St Thomas's Health District Community Health Council and asked what they could do to help. Over four hectic years the club has changed its character and membership several times, but the aims and methods have remained much the same. The aims are to encourage a positive attitude to health, to increase knowledge of the factors affecting it, and to develop the members' self-confidence. The methods are a weekly club where children meet in an informal atmosphere to learn about health and "peer teaching," which means that the members of the club go out to schools and other places to "teach" about health.

\section{The club begins}

When those two boys knocked on its door it reminded the community health council that it was not doing anything for the children in the area. Its first response was to organise immediately a half-term holiday "health event" on teeth, using puppets, models, and demonstrations. From this event and from notices placed in local libraries, schools, and surgeries the club evolved. It started with about 15-20 children aged between 5 and 13 meeting every Tuesday evening for an hour and a half. From February to July 197854 children came to the club, ${ }^{1}$ and over the four years about 200 children have had some contact with it. The organisers have not wanted to classify these children formally in any socioeconomic grouping, but most are "ordinary" Lambeth children. This means that most are working class, and they are of British, Italian, West Indian, Irish, Polish, Cypriot, and Turkish origin. One mentally handicapped girl has attended the club, and there is no evidence that these children are "goody goodies" or in any way very special.

The children have always understood that the club has as a main aim learning about health, and when it started they were asked what topics they would like to cover. Breathing, bones, "my body," nutrition, smoking, and child development were all mentioned. Over the years teeth, nutrition, and the environment have been covered, and the organisers have always been quick to exploit opportunities that arise. The pregnancy of one of the organisers led to the children looking at pregnancy and fetal and child development. The visit of another organiser to Tanzania provided an opportunity to talk about the health problems of poorer countries.

Right from the beginning the organisers have understood that

British Medical Journal, London WC1H 9JR RICHARD SMITH, BSC, MB, assistant editor

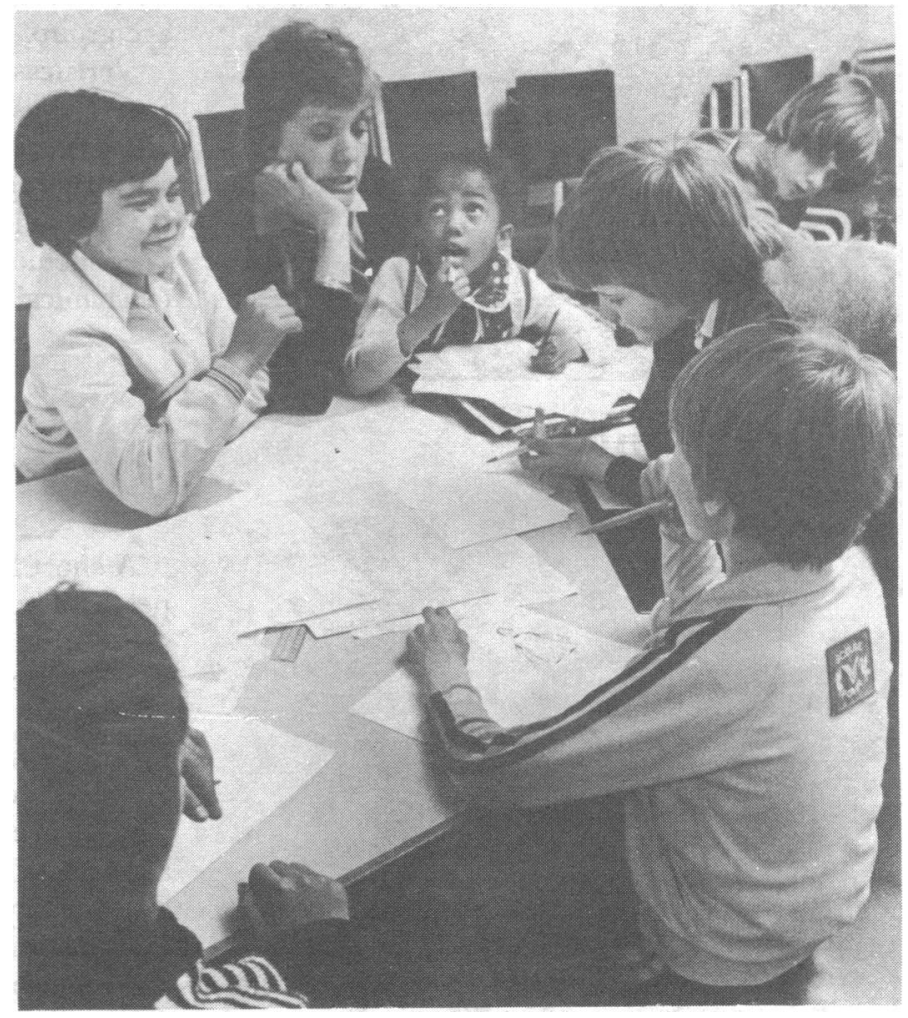

Meeting of the club (photo by Mike Tomlinson).

discussions and didactic teaching are the least successful ways of trying to run a club. Activities have been the key, and the children have painted, made posters, watched films, cooked, produced plays, played games, and been on visits-for example, to a bakers, the Vauxhall City Farm, a sewage farm, and museums. One of the plays the children have produced, one on dental health, has been performed on Nationwide as well as to local groups.

\section{"Peer teaching"}

Something that makes the club very different from school is that the children are given as much responsibility as possible. It is for them to suggest ideas, make decisions, and organise activities, and two are on the project's steering group, one function of which is to interview and select new workers. This theme of responsibility has reached its zenith in the children from the club going out and "teaching" other children about health. Although "peer teaching" has been tried before it has 
usually been limited to literacy tutoring and has not been used for health education. Diane Plamping, a local senior dental officer, who introduced the idea to the club in $1978,{ }^{1}$ struck a bargain with the children, saying that she would run their club if they would help her by teaching other children about dental health.

The children were enthusiastic, and when asked where they would like to teach they suggested the unlikely combination of hospitals, a football ground, libraries, play centres, and sewage farms. They have taught now in schools, hospitals, youth clubs, and the street. For most of the first year they were teaching on dental matters. The children decided whom they wanted to teach and how they would do it, and they came to understand that it was important to have lots of aids and to make the lessons as much fun as possible. To this end they used plaque-disclosing tablets, and models and devised two games-dental bingo, and dental snakes and ladders, where the players go up toothbrushes and down sweets. With the dental bingo the small children call the numbers, and then before they can cover the square the others must answer correctly a question about dental health. In such ways health information is painlessly imparted.

In 1979 the project entered a third phase when the King Edward VII Hospital Fund gave a grant to the club, and a fulltime organiser (Lesley Levane) was appointed. The King's Fund was keen that the project should be evaluated in some way, and it wanted to look at whether peer teaching might be used in other circumstances-for example, nurse training-and what lessons the club could provide for health workers elsewhere in the country. These questions, the club, and its achievements and failures will be discussed at a meeting in London next week (at the King's Fund Centre on 29 September).

Since Lesley Levane was appointed as a full-time organiser the children have moved on to teach on health matters other than teeth. For example, two girls, Aredi and Christine, decided on their own initiative to teach on the five senses. They designed different aids for each of the senses and were almost too successful: the children were so interested in the foods that had to be identified by taste alone that Aredi and Christine had no time left to talk about the other four senses. Other club members designed a method for teaching road safety to very young children and used it at a local nursery. Even the club workers were surprised when two 11-year-old boys, Steven and Lee, taught a group of 13- to 15-year-olds on fetal development using models. They were a little taken aback by the age of their audience but using their script (see fig 2) they were able to talk in a straightforward way about potentially embarrassing subjects; the audience listened attentively. Steven said afterwards, "They didn't know much did they ? I think they learnt a lot though."

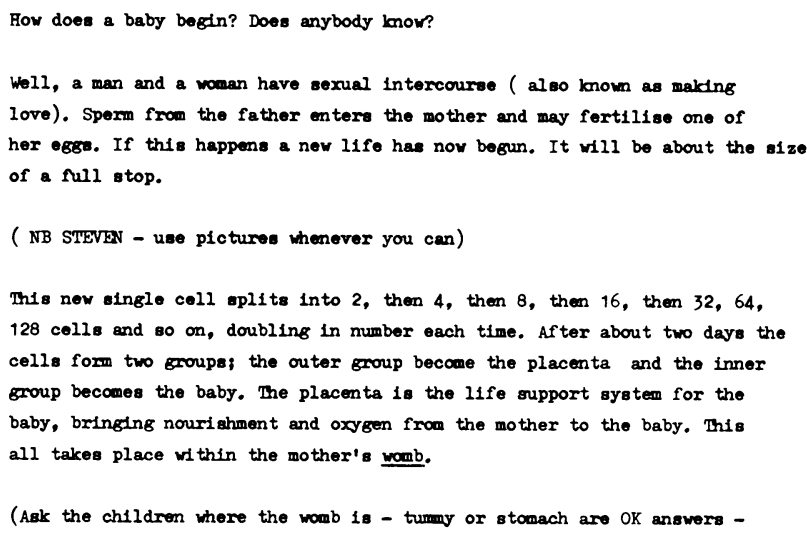

FIG 2-Part of the script used by two boys for teaching on fetal development (written by Steven Dowsett and Lesley Levane).

\section{Room for more clubs}

An evaluation of the club's work has been done and has shown that the children enjoy this kind of health education; they have a more positive approach towards health; they have increased their self-confidence-itself a "healthy" achievement; they have confidence in their own abilities to plan and carry out the teaching; and they link what they learn with their other activities-the club is not just a weekly diversion.

So what does this mean for other people around the country who are interested in health education for children? The first message is that such a project is not difficult to mount: children come forward and enter into the activities with great eagerness. When some of the original members of the Lambeth club moved away or felt too old Lesley Levane arranged to talk to three local schools about the club and attract new members. At the first school she spoke to 100 children and subsequently 30 of them came to the club. She does think, however, that the organisers of the clubs need support and resources; also they need to develop good contacts with both local health workers and the local community. Obviously, too, it is easier for the Lambeth club as it has a full-time organiser. Already other clubs are opening up in South London, and the experience of the Lambeth club does suggest that there is much to be achieved by peer teaching and health clubs for children.

Copies of the report on the club prepared for the King's Fund conference can be obtained from St Thomas's Community Health Council, 2 Cleaver Street, London SE11.

\section{Reference}

1 Plamping D, Thome S, Gelbiev S. Children as dental health educators. Br Dent $\mathcal{F} 1980 ; 149: 113-5$.

Danazol is sometimes used in small doses for breast tenderness and premenstrual tension. While ovulation is usually stopped by this drug, if a woman became pregnant while taking a small dose would the fetus be at risk?

Danazol used in small doses-for example, $100 \mathrm{mg} / \mathrm{day}$-is probably insufficient to inhibit ovulation and therefore pregnancy might occur. There is no animal or human evidence that the drug is teratogenic. It has, however, androgenic properties and therefore should be discontinued as soon as pregnancy is suspected, as otherwise androgenic effects might be produced in a female fetus. I think that, as a general principle, a patient taking a low dose of danazol should be encouraged to avoid pregnancy.

Patients, especially women, often consult me because of sudden abdominal bloating that has no apparent cause but causes them distress. What might be the cause, and what treatment is advised?

Such abdominal distension, which particularly seems to affect women, is always difficult to deal with. In a considerable proportion there are other symptoms of the "irritable bowel" type-namely, erratic bowel habit, particularly constipation, and lower abdominal pain. In others without apparent constipation it can be shown that colon transit time is slow. Acceleration of colon transit time may help in this group, though the introduction of extra dietary fibre may promote gaseous distension because of bacterial action on the fibre. Hydrophilic coloids (methyl cellulose, etc) and osmotic cathartics such as magnesium sulphate may be more useful. In some women distension is the sole symptom, or at least the predominant one, and does not disappear when the bowel habit becomes normal. In some of these the distension is never visible to an outside observer; these women are often tense and introspective, and probably have a disturbed awareness of normal somatic sensation. In others distension may appear profound, especially when standing upright, sometimes often disappearing or diminishing on lying flat. This is due to an exaggerated lordosis. Reassurance and physiotherapy to improve their posture can help. 